\title{
Direitos humanos, atitude institucional e simpatia ideológica em universitários brasileiros
}

\author{
Cleonice Camino \\ Universidade Federal da Paraíba \\ Lilian Galvão \\ Universidade Federal de Campina Grande \\ Gina Quirino \\ Faculdade Integral Diferencial - Teresina, Piauí \\ Raquel Moraes \\ Universidade Estadual da Paraiba \\ Antonio Roazzi \\ Universidade Federal de Pernambuco \\ William Lee B. Martin \\ Universidade Federal do Pará
}

\begin{abstract}
Resumo
Este trabalho teve como objetivo analisar o posicionamento de universitários das regiões norte e nordeste do Brasil sobre os direitos humanos (DH) e a relação desse posicionamento com suas atitudes institucionais, suas simpatias ideológicas e o contexto social em que vivem. Participaram deste estudo 832 universitários do norte e nordeste brasileiro, de ambos os sexos, que responderam a um questionário, contendo escalas que mediam julgamentos sobre 30 direitos, 15 instituições e 10 idéias políticas. Os resultados de uma análise fatorial dos componentes principais sobre os dados referentes aos direitos mostraram a existência de cinco fatores. Os resultados de uma análise de regressão múltipla revelaram a influência das atitudes institucionais e das simpatias ideológicas sobre o envolvimento com os DH; e a influência positiva da região sobre o direito ao protesto social. Os resultados foram discutidos com base em trabalhos empíricos, realizados a partir do referencial psicossociológico.
\end{abstract}

Palavras-chave: direitos humanos; atitude institucional; simpatia ideológica

\begin{abstract}
Human rights, institutional attitudes and ideological sympathies among Brazilian University students. The aim of this article was to ascertain how university students in north and northeastern Brazil view human rights (HR) and the relationship between this variable, institutional attitudes, and ideological sympathies as well as the geographical region in which they live. There were 832 student participants of both sexes that completed a questionnaire measuring their judgments on 30 rights, 15 institutions, and 10 political ideas. A principal components analysis revealed five factors. Results from multiple regression analysis indicated that institutional attitudes and ideological sympathies may have influenced their views on HR, with the geographic region predictive of the right to social protest. These findings are in line with those from other studies and were examined within the framework of psychosociological theory.
\end{abstract}

Keywords: human rights; institutional attitudes; ideological sympathies 
$\mathrm{P}$ ara Doise (2003) os direitos humanos (DH) são vistos como princípios avaliativos ou normativos das representações sociais que podem guiar os humanos, ao menos no nível da intenção, na avaliação de suas organizações e intenções. Os $\mathrm{DH}$, assim definidos, estariam envoltos por definições jurídicas institucionais.

A teoria psicossociológica, a partir da qual Willem Doise estuda os direitos, foi desenvolvida por ele com base na teoria das representações sociais (RS) de Serge Moscovici e na teoria do desenvolvimento sócio-cognitivo de Jean Piaget. Para Doise (2001), as concepções sobre os DH surgem como formas de compromisso que têm por finalidade a justiça nas relações. Essas concepções, ao cristalizarem-se - após várias lutas orientadas, de um lado, por idéias liberais e, de outro, por idéias tradicionais -, foram culturalmente definidas e acompanhadas por exigências para o seu cumprimento, tornando-se institucionalizadas. Esta institucionalização ocorreu com o apoio de 48 Estados, através da Declaração Universal dos Direitos Humanos (DUDH), em 1948.

O consenso dos Estados em torno da Declaração indica, para Bobbio (1992), que um sistema de valores é criado, pela primeira vez na história universal, não em princípio, mas de fato, na medida em que o consenso sobre sua validade e capacidade para reger os destinos futuros de todos os homens foi explicitamente declarado. Entretanto, para ele universal não significa algo dado objetivamente, mas algo que pode ser subjetivamente acolhido pelo universo dos homens. O que não quer dizer que os DH sejam conhecidos, valorizados e respeitados por todos.

A tese do universalismo tem sido um tema controverso: é sustentada por alguns, como é o caso de Comparato (1997), que defende até mesmo o fundamento absoluto dos $\mathrm{DH}$; e criticada por outros, como é o caso de Zollo (2006), que aponta para diferentes dificuldades relativas à aplicabilidade dos direitos.

De fato, a implementação dos direitos é quase um ideal utópico. É sabido que no Brasil, por exemplo, como mostra o $3^{\circ}$ Relatório Internacional sobre os Direitos Humanos (Núcleo de Estudos da Violência, 2005), a violação dos DH é uma realidade incontestável. Segundo esse relatório, de 2002 a 2005 houve um recesso no desenvolvimento de políticas de proteção e promoção dos DH: aumento da violência praticada com uso de armas de fogo contra crianças e adolescentes; aumento das denúncias de abuso e exploração sexual de crianças e adolescentes; aumento do trabalho infantil; persistência do trabalho escravo em todas as regiões do país; intensificação dos conflitos pela posse de terras; intensificação na superlotação de unidades penitenciárias.

Apesar desse tema de violação merecer toda a atenção dos estudiosos, não é pretensão deste trabalho investigá-lo. Por outro lado, não é pretensão deste estudo defender a universalização, com base no direito fundamental à dignidade humana, e nem mesmo o de defender que os DH devam ser acolhidos por todos. Simplesmente, tem-se como objetivo verificar o quanto os $\mathrm{DH}$ são valorizados em alguns segmentos da sociedade brasileira (norte e nordeste), já que é uma pretensão da DUDH que eles venham a ser conhecidos e valorizados universalmente. Aliás, sem serem conhecidos e valorizados não poderão ser respeitados.

Concretamente, o presente trabalho abordou o posicionamento de estudantes universitários das regiões norte e nordeste do Brasil sobre os DH e a relação desse posicionamento com as atitudes institucionais, as simpatias ideológicas e o contexto social em que vivem.

Esses objetivos têm também constituído a meta de várias pesquisas da área da psicologia social, cujos pesquisadores têm-se indagado sobre alguns aspectos relativos aos DH. Qual a representação que os indivíduos têm dos direitos humanos? Qual o posicionamento e o respeito dos indivíduos pelos $\mathrm{DH}$ ? Qual a visão dos indivíduos sobre a violação dos DH? Quais os princípios organizadores dos DH? Quais os fatores que podem influenciar em um maior ou menor envolvimento das pessoas com os DH?

Com o intuito de responder a essas questões, Doise, Clémence e Lorenzi-Cioldi (1992) elaboraram um método que utiliza três níveis de análise: (a) verificação de um consenso sobre as representações sociais dos $\mathrm{DH}$; (b) verificação das diversidades das tomadas de posições individuais sobre os $\mathrm{DH}$ - princípios organizadores dos $\mathrm{DH}$-, isto é, verificação das modulações de um campo de representações partilhadas; (c) verificação da relação entre as RS dos DH e variáveis sóciodemográficas e psicossociológicas, a partir da suposição de que as inserções sociais partilhadas dão lugar à experiência e interações específicas que, através da intervenção diferenciada de valores, crenças e percepções sociais, transformam as RS.

No item $c$, são consideradas, dentre as variáveis sóciodemográficas, o contexto social e, dentre as variáveis psicossociológicas, a atitude institucional - posicionamento dos indivíduos a respeito de diferentes instituições, como escola, hospitais, família, tribunais, ONU, plano de saúde, banco, cruz vermelha, movimentos ecológicos, televisão, jornais, religião, partidos políticos, organizações femininas e associações esportivas -, e a simpatia ideológica - atitude em relação aos partidos de esquerda e de direita, avaliada por Doise (2001), por meio das idéias de forças, como, por exemplo, liberdade, solidariedade, igualdade, democracia, poder, dinheiro e tradições, que compõem as ideologias partidárias.

Esse método de análise orientou várias pesquisas (Camino, Pereira \& Paz, 2001; Clémence, Doise, De Rosa \& Gonzalez, 1995; Doise, 2001; Doise, Staerklé, Clémence \& Savory, 1998) e também o presente trabalho.

Clémence et al. (1995) procuraram verificar se diferentes contextos (Costa Rica, França, Itália e Suíça) influenciavam no grau em que jovens de 13 a 20 anos de idade, de ambos os sexos avaliavam 21 proposições como sendo violações dos DH, ou não.

Uma análise dos dados da pesquisa de Clémence et al. (1995) indicou que 80,9\% das proposições foram julgadas, em média, por $69,5 \%$ dos estudantes, como um atentado aos DH. Como essas proposições foram baseadas na DUDH, esses resultados indicaram que houve correspondência elevada entre a representação dos $\mathrm{DH}$ pelos estudantes e os $\mathrm{DH}$ constituintes da DUDH e que, portanto, a concepção de universalismo dos DH era corroborada.

Em um outro estudo, Doise et al. (1998) investigaram o posicionamento de 849 estudantes suíços, com idade variando de 12 a 21 anos, sobre os DH. A estes estudantes, administraram 
um questionário composto de diferentes partes. Uma das partes era constituída por uma lista de 30 direitos, retirados da DUDH, para verificar o quanto esses direitos eram considerados como protótipos. Os alunos deveriam indicar, para cada um dos direitos, sobre uma escala de quatro pontos, se o direito constituía um bom ou um mau exemplo dos direitos do homem. Em uma outra parte do questionário, os estudantes deveriam indicar, em uma lista, na qual eram elencadas 15 instituições, em que grau cada instituição era útil para ele pessoalmente e, a seguir, em uma outra lista, em que grau as 15 mesmas instituições eram úteis para a vida social. Finalmente, era solicitado aos sujeitos que informassem sobre questões sócio-demográficas e sóciopsicológicas.

Os dados referentes à lista dos 30 direitos foram submetidos a uma análise fatorial de componentes principais (AFCP). Nos resultados, Doise et al. (1998) constataram que os DH agrupavam-se em cinco fatores: Direitos Concretos (ter um ambiente saudável, escolher suas roupas, viver em um mundo em paz, ter um cachorro, ter um emprego, viver com sua família, estudar na língua materna, escolher o país para morar); Direito de Recusar Intervenções Médicas e Militares (recusar uma vacina, esconder doença contagiosa, fumar, recusar serviço militar); Protesto Social (fazer greve, organizar manifestações); Contestação na Escola (disputar notas escolares, recusar ir à escola, legítima defesa) e Escolhas em Questões Relativas à Vida (ajudar a morrer uma pessoa seriamente enferma que pede para morrer, abortar, escolher religião, ter quantas crianças desejar), os quais foram considerados como princípios organizadores dos direitos.

Os resultados da análise com as instituições indicaram a existência de quatro fatores, tanto para as instituições tidas como de utilidade pessoal, como para as tidas como de utilidade social. Os fatores de utilidade pessoal foram denominados: Organização Pública (ONU, Cruz Vermelha, movimentos ecológicos, partidos políticos, organizações femininas e tribunal); Finanças/Mídia (bancos, planos de saúde, televisão, jornais); Instituições Próximas (escolas e hospitais) e Vida Privada (associações esportivas, família e religião). Os fatores das instituições de utilidade social receberam as mesmas denominações, porém houve uma ligeira modificação na composição de cada fator.

Em uma análise dessa pesquisa sobre o processo de ancoragem dos DH nas instituições, Doise et al. (1998) constataram, dentre outros resultados, que uma maior atribuição da utilidade da escola, uma maior favorabilidade aos movimentos ecológicos e às organizações femininas, associava-se negativamente à consideração prototípica dos direitos concretos e de recusa. Verificaram também que a religião seguia esse mesmo padrão de associação, exceto no que dizia respeito ao direito de recusa em que a associação foi negativa.

Frente a esses resultados, Doise et al. (1998) julgaram que a escolha dos direitos concretos como prototípicos refletia uma atitude pouco crítica da ordem estabelecida, a qual poderia ser alterada com a socialização dos indivíduos através da escola e da participação nos partidos políticos. Além disso, os autores chamaram a atenção para a importância atribuída aos partidos políticos e à escola na escolha dos direitos fundamentais e públicos.
Posteriormente, Doise (2001) reavaliou dados daquela pesquisa anterior (Doise et al.,1998) acerca das instituições sócio-políticas. Nesta, ele efetuou uma análise fatorial sobre o conjunto das respostas às questões relativas às instituições de utilidade privada e de utilidade social. Nos resultados, constatou a existência de 10 fatores: o primeiro fator foi constituído pelas escalas de utilidade privada e social da Cruz Vermelha, dos hospitais, dos movimentos ecológicos, da ONU e dos tribunais; o segundo foi constituído pelas mesmas instituições do primeiro, com exceção dos movimentos ecológicos de utilidade privada; $\mathrm{o}$ terceiro incluiu os planos de saúde e bancos (ambos de utilidade privada e social); o quarto associou as respostas dadas nas escalas de utilidade privada e social relativas à mídia, aos jornais e à televisão; o quinto incluiu as organizações femininas de utilidade privada e social e os movimentos ecológicos de utilidade pessoal; o sexto foi formado pela escola de utilidade privada e social; o sétimo, pela religião de utilidade privada e social; o oitavo, pelas associações esportivas de utilidade privada e social; o nono, pelos partidos políticos de utilidade privada e social; e o décimo, pela família de utilidade privada e social.

Camino et al. (2001) realizaram uma pesquisa com 403 estudantes, de ambos os sexos, alunos da $2^{\mathrm{a}}$ série do ensino fundamental e da $7^{\mathrm{a}}$ série do ensino médio. Os alunos responderam sobre a importância dos DH e da atitude institucional a partir do questionário elaborado por Doise et al. (1998). Os dados obtidos foram submetidos a uma AFCP depois de retirar deles os direitos que foram considerados como exemplares pela maioria dos estudantes. Os resultados da AFCP indicaram, semelhantemente aos de Doise et al. (1998), a existência de cinco fatores: Concretos (escolher suas roupas, ter um cachorro, proteção contra a violência, eleger o governo, ser o que quiser, ser defendido no tribunal, a propriedade); Decisões sobre a Vida (abortar, eutanásia, fumar, escolher sua religião, recusar serviço militar); Protesto Social (organizar manifestações, fazer greve, participar de um sindicato); Contestação Escolar (discordar de notas escolares, legítima defesa, recusar ir à escola, morar no país que quer) e Recusar Intervenções Médicas (recusar vacina, esconder doença contagiosa, ter quantos filhos desejar).

Os resultados de uma AFCP sobre os dados da atitude institucional dos estudantes indicaram, diferentemente dos de Doise (2001), a presença de oito fatores, quatro referentes à utilidade pessoal das instituições: Instituições Públicas (Cruz Vermelha, movimentos ecológicos, partidos políticos, tribunais); Lazer/Finanças (associações esportivas, bancos e TV); Instituições de Proteção (família, religião, plano de saúde, hospitais) e Cultura/Informação (jornais e escola); e quatro referentes à utilidade social: Instituições Públicas (partidos políticos, bancos, tribunais); Bem-Estar/Informação (movimentos ecológicos, associações esportivas, TV e jornais); Instituições de Proteção (família, religião, hospitais) e Organizações Humanitárias (ONU, movimentos ecológicos, Cruz Vermelha).

As pesquisas aqui apresentadas revelam, de uma forma geral, a difusão do conhecimento sobre os DH, a existência dos princípios organizadores dos $\mathrm{DH}$, de princípios que organizam a atitude institucional, e da ancoragem dos DH em variáveis psicossociais e sócio-demográficas. Considerando que ainda 
são raras no Brasil as pesquisas que analisam os aspectos supracitados referentes aos $\mathrm{DH}$, que é essencial para uma prática educativa voltada aos DH conhecer melhor os fatores que os influenciam, e que o conhecimento desses fatores também é importante do ponto de vista teórico, julgou-se relevante efetuar uma pesquisa com os seguintes objetivos: (1) verificar os princípios organizadores das Representações Sociais (RS) dos DH em universitários do Brasil; (2) verificar se existe diferença cultural (norte e nordeste) com relação aos princípios organizadores das RS dos DH; e (3) verificar a ancoragem dos princípios organizadores das $\mathrm{RS}$ dos $\mathrm{DH}$ na atitude institucional e na simpatia ideológica sobre os $\mathrm{DH}$.

\section{Método}

\section{Participantes}

Fizeram parte deste estudo 832 alunos, sendo 596 (71\%) do sexo feminino e 240 (29\%) do sexo masculino, com idade média de 24,6 anos $(D P=6,5)$, matriculados, sobretudo, em cursos da área de Ciências Humanas, em universidades públicas das cidades de João Pessoa ${ }^{1}$ (46,3\%), Recife ${ }^{1}(13,4 \%)$, Teresina ${ }^{1}$ (10,1\%), Salvador ${ }^{1}(7,8 \%)$, Natal ${ }^{1}(5,5 \%)$, Belém $^{2}(8,1 \%)$, e em uma universidade particular de Manaus $^{2}(8,8 \%)$.

\section{Instrumentos}

Na coleta de dados, foi utilizado um questionário elaborado por Doise et al. (1998) e adaptado por Camino (2002), formado por três partes, reproduzidas no Apêndice.

$\mathrm{Na}$ primeira, o respondente deveria avaliar 34 direitos e indicar, em uma escala de quatro pontos, se considerava um bom ou mau exemplo de direito.

$\mathrm{Na}$ segunda, que continha uma lista de 15 instituições (ver Apêndice), o respondente deveria marcar, em uma escala de quatro pontos, o grau em que cada instituição era útil para sua vida pessoal e, em seguida, deveria atribuir o grau de utilidade destas mesmas instituições para sua vida em sociedade.

$\mathrm{Na}$ última parte, foram propostas 10 idéias (liberdade, solidariedade, direitos do homem, partido de direita, igualdade, democracia, poder, dinheiro, partido de esquerda e tradições), retiradas do domínio político, para que os estudantes indicassem seu grau de simpatia por elas, a partir de uma escala de quatro pontos, que variava de 1 (eu não gosto de forma nenhuma) a 4 (eu gosto muito). Havia, ainda, uma alternativa para que o respondente assinalasse quando ele desconhecesse a idéia.

\section{Procedimentos}

Os instrumentos foram aplicados, de forma coletiva, por professores das diferentes universidades em que os participantes estudavam.

\section{Resultados}

Foram realizadas, inicialmente, análises fatoriais dos componentes principais (AFCP), com rotação varimax, sobre os dados referentes aos direitos humanos, à atitude institucional - atribuição de utilidade social e pessoal a determinadas organizações - e à simpatia por determinadas idéias (democracia, igualdade, poder, etc.). Após cada AFCP, foram calculadas as médias de escores para cada fator e a diferença entre as médias, através do teste $t$ ou da análise de variância (ANOVA), acompanhada do teste a posteriori de Scheffé.

Antes da realização da AFCP, verificaram-se quais os direitos que $85 \%$ ou mais dos estudantes julgaram como sendo um bom exemplo de direito. Os resultados dessa análise mostraram os seguintes direitos consensuais: cuidados médicos, ser defendido em tribunal, ter o que comer, diversões, eleger governo, ter um emprego, viver com a família, viver em um ambiente saudável, viver em um mundo em paz, ter proteção da polícia contra a violência, não ser discriminado pela sua cor, moradia, ter o que vestir, ter um salário digno, estudar.

Os resultados da AFCP para a verificação dos princípios organizadores das RS dos DH, feita com os escores dos direitos não consensuais, mostraram a existência de cinco fatores que explicaram $49 \%$ da variância total, todos com autovalores superiores a 1, denominados: Decisões Relativas à Vida, Protesto Social, Direitos Concretos, Recusa de Controle Social e Defesa Pessoal (ver Tabela 1).

Também se efetuou uma ANOVA para medidas repetidas, cujos resultados mostraram uma diferença significativa entre as médias fatoriais $\left(F_{4827}=1019,233 ; p<0,05\right)$. Com o teste de Scheffé, verificou-se que as médias mais altas referiam-se aos direitos agrupados nos fatores Defesa Pessoal e Direitos Concretos, que não se diferenciaram entre si, e foram seguidas pela média do Protesto Social, que foi significativamente superior à média de Recusa de Controle Social. Esta, por sua vez, foi significativamente superior à média do fator Decisões Relativas à Vida.

A AFCP com os dados relativos à atitude institucional (atribuição da utilidade social e da utilidade pessoal) revelou a existência de 10 fatores (Tabela 2), que foram denominados: Organizações Básicas, Organizações de Defesa Social, Finanças, Organizações Humanitárias, Mídia, Organizações de Defesa Pessoal, Religião, Partidos Políticos, Organizações Femininas e Associações Esportivas. Esses fatores explicaram 66\% da variância total e apresentaram autovalores superiores a 1 .

Uma ANOVA para medidas repetidas mostrou diferenças significativas entre as médias de vários fatores $\left(F_{9822}=221,288\right.$; $p<0,05)$. Segundo o teste de Scheffé, a média que se mostrou significativamente mais elevada foi a do fator institucional Organizações Básicas, seguida da média do fator Religião, que foi seguida das médias iguais dos fatores Organizações de Defesa Social, Organizações Humanitárias, Organizações de Defesa Pessoal e Finanças. Logo após, vieram as médias das Organizações Femininas e Associações Esportivas e Mídia, que, embora não tenham se diferenciado significativamente das médias do fator Finanças, diferenciaram-se dos outros fatores. Por fim, a média do fator Partidos Políticos foi a menor de todas.

Uma outra AFCP, utilizando os dados da simpatia por determinadas idéias (simpatia ideológica), indicou a existência de dois fatores, que explicaram $41,75 \%$ da variância total, o primeiro com $27,25 \%$ e o segundo com $14,49 \%$, ambos com autovalores superiores a 1 . O primeiro fator é formado pelas idéias de liberdade, solidariedade, direitos do homem, igualdade e democracia e foi denominado Liberalista. O segundo, constituído pelas idéias de poder, dinheiro, partidos de direita e 
Tabela 1

Análise fatorial dos componentes principais dos 19 direitos não-consensuais $(N=832)$

\begin{tabular}{|c|c|c|c|c|c|}
\hline Direitos & $\begin{array}{c}\text { Decisões } \\
\text { Relativas à Vida }\end{array}$ & $\begin{array}{c}\text { Protesto } \\
\text { Social }\end{array}$ & $\begin{array}{l}\text { Direitos } \\
\text { Concretos }\end{array}$ & $\begin{array}{c}\text { Recusa de } \\
\text { Controle Social }\end{array}$ & $\begin{array}{l}\text { Defesa } \\
\text { Pessoal }\end{array}$ \\
\hline Abortar & 0,74 & & & & \\
\hline Fumar & 0,69 & & & & \\
\hline Recusar ir à escola & 0,65 & & & & \\
\hline Apressar a morte de um doente terminal & 0,63 & & & & \\
\hline Recusar vacina & 0,51 & & & & \\
\hline Recusar serviço militar & 0,40 & & & & \\
\hline Escolher sua religião & 0,39 & & & & \\
\hline Organizar manifestações & & 0,82 & & & \\
\hline Fazer greve & & 0,77 & & & \\
\hline Fazer parte de um sindicato & & 0,73 & & & \\
\hline Escolher suas roupas & & & 0,72 & & \\
\hline Ter um cachorro & & & 0,70 & & \\
\hline Morar no país que se quer & & & 0,61 & & \\
\hline Discordar das notas da escola & & & 0,49 & & \\
\hline Ter quantos filhos quiser & & & & 0,70 & \\
\hline Esconder doença contagiosa & & & & 0,65 & \\
\hline Ser o que quiser & & & & 0,36 & \\
\hline Legítima defesa & & & & & 0,80 \\
\hline Propriedade & & & & & 0,42 \\
\hline Variância explicada (49\%) & $14 \%$ & $11 \%$ & $10 \%$ & $8 \%$ & $6 \%$ \\
\hline Médias & 1,7 & 3,1 & 3,2 & 2,3 & 3,2 \\
\hline Desvio Padrão & 0,7 & 0,7 & 0,5 & 0,6 & 0,7 \\
\hline
\end{tabular}

$\mathrm{KMO}=0,780$

tradições, foi denominado Tradicionalista. A idéia partidos de esquerda não entrou em nenhum dos fatores, por apresentar um nível de saturação inferior a 0,35 (nível de saturação escolhido para ponto de corte).

A comparação entre os dois fatores indicou que houve uma média significativamente mais elevada de respostas $(t=58,4 ; \mathrm{gl}$ =794; $p<0,05 ; N=832)$ para o fator Liberalista $(M=3,7 ; D P=$ $0,43)$ do que para o fator Tradicionalista $(M=2,5 ; D P=0,49)$.

Após estas análises, realizou-se uma análise de regressão múltipla (ARM) para verificar a ancoragem dos princípios organizadores das RS dos $\mathrm{DH}$ na atitude institucional e na simpatia ideológica (liberalismo-conservadorismo), consideradas como variáveis preditoras, sobre os princípios referentes aos $\mathrm{DH}$, considerados como variáveis dependentes. Os resultados dessa análise (Tabela 3 ) indicaram que as variáveis preditoras influenciaram significativamente $(p<0,05)$, tanto de forma positiva, como de forma negativa, os princípios organizadores dos DH. A seguir, apresenta-se um resumo desses resultados: (1) a atitude favorável às Organizações Humanitárias influenciou positivamente o Protesto Social e os Direitos Concretos; (2) a atitude favorável às Organizações Femininas influenciou positivamente o Protesto Social, os Direitos Concretos e a
Recusa de Controle Social; (3) a atitude favorável à Religião influenciou negativamente as Decisões Relativas à Vida, os Direitos Concretos e a Defesa Pessoal; (4) a atitude favorável aos Partidos Políticos influenciou positivamente as Decisões Relativas à Vida e o Protesto Social; (5) a atitude favorável às Associações Esportivas influenciou positivamente os Direitos Concretos; (6) a atitude favorável às Organizações de Defesa Social influenciou negativamente o Protesto Social, os Direitos Concretos e a Defesa Pessoal; (7) a atitude favorável às Finanças influenciou negativamente as Decisões Relativas à Vida e o Protesto Social; (8) a atitude favorável às Organizações de Defesa Pessoal influenciou positivamente os direitos relativos à Defesa Pessoal; (9) a simpatia pelo liberalismo influenciou positivamente todos os princípios organizadores dos $\mathrm{DH}$, com exceção da Defesa Pessoal.

Além da atitude institucional e da simpatia ideológica, verificou-se a influência positiva da região sobre os direitos ao Protesto Social (organizar manifestações, fazer greve, fazer parte de um sindicato). Os resultados de uma ANOVA indicaram que a região nordeste influenciou mais o Protesto Social do que a região norte: $F_{1,817}=6,29 ; p<0,05$. 
Tabela 2

Análise fatorial dos componentes principais das instituições de utilidade pessoal e de utilidade social

\begin{tabular}{|c|c|c|c|c|c|c|c|c|c|c|}
\hline Instituições & 1 & 2 & 3 & 4 & 5 & 6 & 7 & 8 & 9 & 10 \\
\hline Escola $(\mathrm{P})$ & 0,78 & & & & & & & & & \\
\hline Hospitais $(\mathrm{P})$ & 0,71 & & & & & & & & & \\
\hline Escola (S) & 0,61 & & & & & & & & & \\
\hline Família (P) & 0,53 & & & & & & & & & \\
\hline Família (S) & 0,51 & & & & & & & & & \\
\hline Tribunais $(\mathrm{S})$ & & 0,60 & & & & & & & & \\
\hline Hospitais (S) & & 0,59 & & & & & & & & \\
\hline ONU (S) & & 0,58 & & & & & & & & \\
\hline Planos de saúde (S) & & & 0,80 & & & & & & & \\
\hline Planos de saúde $(\mathrm{P})$ & & & 0,77 & & & & & & & \\
\hline Bancos (S) & & & 0,59 & & & & & & & \\
\hline Bancos $(\mathrm{P})$ & & & 0,56 & & & & & & & \\
\hline Cruz-vermelha (P) & & & & 0,74 & & & & & & \\
\hline Cruz-vermelha (S) & & & & 0,73 & & & & & & \\
\hline Movim. ecológicos $(\mathrm{P})$ & & & & 0,61 & & & & & & \\
\hline Movim. ecológicos (S) & & & & 0,55 & & & & & & \\
\hline Televisão (P) & & & & & 0,73 & & & & & \\
\hline Televisão (S) & & & & & 0,69 & & & & & \\
\hline Jornais (S) & & & & & 0,56 & & & & & \\
\hline Jornais $(\mathrm{P})$ & & & & & 0,51 & & & & & \\
\hline ONU (P) & & & & & & 0,74 & & & & \\
\hline Tribunais $(\mathrm{P})$ & & & & & & 0,63 & & & & \\
\hline Religião (S) & & & & & & & 0,82 & & & \\
\hline Religião (P) & & & & & & & 0,79 & & & \\
\hline Partidos políticos $(\mathrm{P})$ & & & & & & & & 0,79 & & \\
\hline Partidos políticos (S) & & & & & & & & 0,75 & & \\
\hline Organizações femininas $(\mathrm{P})$ & & & & & & & & & 0,84 & \\
\hline Organizações femininas (S) & & & & & & & & & 0,83 & \\
\hline Associações esportivas (S) & & & & & & & & & & 0,83 \\
\hline Associações esportivas (P) & & & & & & & & & & 0,81 \\
\hline Variância Explicada (66\%) & $9 \%$ & $8 \%$ & $7 \%$ & $7 \%$ & $7 \%$ & $6 \%$ & $6 \%$ & $6 \%$ & $5 \%$ & $5 \%$ \\
\hline Médias & 3,6 & 2,9 & 2,7 & 2,8 & 2,7 & 2,8 & 3,1 & 2,3 & 2,7 & 2,7 \\
\hline Desvio Padrão & 0,5 & 0,7 & 0,7 & 0,6 & 0,6 & 0,7 & 0,8 & 0,8 & 0,8 & 0,7 \\
\hline
\end{tabular}

$\mathrm{KMO}=0,756$

P: Instituições de utilidade pessoal

S: Instituições de utilidade social

Fator 1: Organizações Básicas

Fator 2: Organizações de Defesa Social

Fator 3: Finanças

Fator 4: Organizações Humanitárias

Fator 5: Mídia

Fator 6: Organizações de Defesa Pessoal

Fator 7: Religião

Fator 8: Partidos Políticos

Fator 9: Organizações Femininas

Fator 10: Associações Esportivas 


\section{Discussão}

Uma comparação quantitativa entre os direitos consensuais obtidos nesse trabalho e no trabalho de Doise et al. (1998) indica que na amostra brasileira houve um maior número de respostas consensuais $(44 \%)$ do que na dos estudantes suíços $(27 \%)$. Acredita-se que isso se deva a uma maior carência dos brasileiros na satisfação de seus direitos básicos.

Os resultados da AFCP, para verificar os princípios organizadores das RS dos direitos, mostraram a existência de cinco fatores, como nos trabalhos de Doise et al. (1998), com estudantes (12 a 21 anos), e de Camino et al. (2001), com estudantes (13 a 18 anos). Entretanto, quando se consideram os tipos de fatores encontrados nessas duas pesquisas, nota-se que existe semelhança apenas entre três fatores. Observa-se, também, quando são comparados os dados da atual pesquisa com os de Camino et al., uma correspondência em relação aos mesmos três fatores. Porém, quando são comparados os dados de Doise et al. com os de Camino et al., observa-se uma semelhança entre quatro fatores. $\mathrm{O}$ fato de se ter encontrado maior semelhança entre os genebreses (12 a 21 anos) e os pessoenses (13 a 18 anos), parece indicar que a idade, o nível de escolaridade e as experiências institucionais afetam mais a configuração dos princípios organizadores do que a cultura.

A AFCP das respostas relativas às instituições revelou a existência de 10 fatores, o que confirma os resultados obtidos por Doise (2001). Destes, cinco fatores foram exatamente idênticos aos obtidos por este autor: Finanças, Mídia, Religião, Partidos Políticos e Associações Esportivas. Os outros apresentaram algumas diferenças. Dentre as diferenças observadas, chama a atenção o fato de que, no trabalho de Doise, Escola e Família constituem dois fatores diferentes, enquanto no presente trabalho fazem parte de um único fator, juntamente com a instituição

Tabela 3

Regressões múltiplas para verificar a influência das instituições de utilidade pessoal e social, das simpatias ideológicas e da região nos princípios organizadores dos direitos

\begin{tabular}{|c|c|c|c|c|}
\hline Variáveis Antecedentes & Variáveis Dependentes & $B$ & $t$ & sig. \\
\hline Religião & Decisões Relativas à Vida & $-0,36$ & $-10,32$ & 0,00 \\
\hline Partidos Políticos & & 0,124 & 3,59 & 0,00 \\
\hline Liberalismo & & 0,096 & 2,85 & 0,00 \\
\hline Finanças & & $-0,074$ & $-2,08$ & 0,04 \\
\hline Organizações Femininas & Protesto Social & 0,17 & 4,57 & 0,00 \\
\hline Partidos Políticos & & 0,15 & 4,13 & 0,00 \\
\hline Finanças & & $-0,14$ & $-3,51$ & 0,00 \\
\hline Organizações Humanitárias & & 0,14 & 3,64 & 0,00 \\
\hline Região & & 0,09 & 2,55 & 0,01 \\
\hline Liberalismo & & 0,09 & 2,73 & 0,01 \\
\hline Organizações de Defesa Social & & $-0,09$ & $-2,23$ & 0,03 \\
\hline Mídia & Direitos Concretos & 0,20 & 5,13 & 0,00 \\
\hline Organizações Humanitárias & & 0,15 & 3,95 & 0,00 \\
\hline Organizações de Defesa Social & & $-0,19$ & $-4,40$ & 0,00 \\
\hline Liberalismo & & 0,15 & 4,27 & 0,00 \\
\hline Associações Esportivas & & 0,11 & 2,87 & 0,00 \\
\hline Religião & & $-0,08$ & $-2,16$ & 0,03 \\
\hline Organizações Femininas & & 0,08 & 2,08 & 0,04 \\
\hline Liberalismo & Recusa de Controle Social & 0,14 & 3,86 & 0,00 \\
\hline Organizações Femininas & & 0,08 & 2,10 & 0,04 \\
\hline Organizações de Defesa Pessoal & Defesa Pessoal & 0,12 & 2,98 & 0,00 \\
\hline Organizações de Defesa Social & & 0,09 & 2,38 & 0,02 \\
\hline Religião & & 0,08 & 2,08 & 0,04 \\
\hline $\begin{array}{ll}\text { Fator 1: } R=0,388 & R^{2}=0,150 \\
\text { Fator 2: } R=0,327 & R^{2}=0,107 \\
\text { Fator 3: } R=0,330 & R^{2}=0,110\end{array}$ & \multicolumn{4}{|c|}{$\begin{array}{ll}\text { Fator 4: } R=0,161 & R^{2}=0,026 \\
\text { Fator 5: } R=0,218 & R^{2}=0,048\end{array}$} \\
\hline
\end{tabular}


hospitalar de utilidade pessoal. Acredita-se que a associação dessas instituições em um único fator deva-se ao fato de que, no Brasil, aqueles que possuem atendimento hospitalar público possuem, também, educação escolar (do ensino fundamental e médio) pública, por serem de condição sócio-econômica desfavorecida; ocorrendo o inverso (atendimento hospitalar e educação privados) com aqueles que possuem melhor condição sócio-econômica. Uma outra razão para que estas instituições, na presente pesquisa, apareçam associadas parece estar relacionada ao fato de que saúde e escola apresentam-se como necessidades básicas não satisfeitas para a maioria das famílias brasileiras.

Em relação à AFCP dos dados das simpatias ideológicas, denominadas por Doise et al. (1998) idéias de força, foi verificada a existência de dois fatores. $O$ primeiro fator, formado pela solidariedade, liberdade, igualdade, direitos do homem e democracia, revela idéias que estão na base da própria DUDH, o que permitiu considerá-lo como um fator positivo dos direitos e denominá-lo de Liberalista. Já o segundo fator, que se encontra formado por idéias relativas ao poder, dinheiro, partidos de direita e tradições, que, na luta histórica pelos direitos humanos, apareceram associadas a uma oposição a esses direitos, foi considerado como um fator antagônico e denominado de Tradicionalista. Esses resultados, apesar da análise estatística não ter sido a mesma, são compatíveis com os encontrados por Doise et al., que os denominaram, respectivamente, Coletivismo e Apolitismo.

Os resultados da ARM, para verificar a ancoragem dos princípios organizadores das RS dos $\mathrm{DH}$ nas variáveis psicossociológicas (atitude institucional e simpatia ideológica), permitiram, primeiramente, verificar que as Organizações Básicas, onde está inserida a escola, não exerce influência no envolvimento com os $\mathrm{DH}$. Este resultado difere daquele observado nos adolescentes genebreses (Doise, 2001), em que a escola exerce influência positiva em relação aos direitos fundamentais e públicos e negativa em relação aos direitos concretos e de recusa. Considerando que as Organizações Básicas foi o fator que obteve os escores médios mais elevados, julga-se que a pouca variação desses escores foi responsável pela falta de relação entre as Organizações Básicas e os DH.

Em seguida, verificou-se que a adesão às Organizações de Defesa Social exerceu um efeito positivo sobre o fator Defesa Pessoal, o que seria de se esperar, devido à participação neste fator do direito a ser julgado por um tribunal; e exerceu um efeito negativo sobre os Direitos Concretos e o Protesto Social. Julga-se que a influência negativa das Organizações de Defesa Social sobre os Direitos Concretos poderia significar uma maior visão política dos estudantes, uma vez que, segundo Doise et al. (1998), a adesão aos Direitos Concretos revela uma atitude pouco crítica dos respondentes. Mas, se esta interpretação é correta, por que a influência negativa sobre o Protesto Social? É possível que, no Brasil, não exista uma visão diferenciada entre Direitos Concretos e Protesto Social. Observe-se, neste sentido, que a média dos Direitos Concretos é a mais elevada ( $M$ $=3,2$ ), porém que ela é seguida, imediatamente, pela média do direito ao Protesto Social $(M=3,3)$. Ainda em relação a essa não diferenciação, deve-se notar que os estudantes das universidades públicas, no Brasil, são, em sua grande maioria, provenientes de famílias das classes média e alta, e que, portanto, são habituados a um estilo de vida consumista. Porém, ao entrar na universidade, começam a ouvir e a aderir a um discurso favorável aos partidos de esquerda, que é majoritário nas universidades públicas (Da Costa, Torres, Burity, \& Camino, 1994).

A Mídia (televisão e jornais) exerceu um efeito positivo no envolvimento com os Direitos Concretos. Não é surpreendente constatar o efeito positivo da Mídia sobre esses direitos, uma vez que a TV enfatiza valores próprios da ideologia dominante, do capitalismo, o que significa a veiculação de valores ligados ao consumismo.

As Organizações Humanitárias tiveram um efeito positivo sobre o Protesto Social e os Direitos Concretos, recobrindo, portanto, dois campos distintos dos direitos, o que mostra um forte poder de socialização destas organizações. Ademais, estes resultados parecem indicar, como os anteriores, que aderir a um pensamento defendido pelos partidos de esquerda não exclui a adesão a um pensamento voltado para interesses consumistas.

A Religião exerceu um efeito negativo nos diretos referentes às Decisões Relativas à Vida e em relação aos Direitos Concretos, e positivo em relação à Defesa Pessoal. A influência negativa sobre os Direitos Relativos à Vida também foi encontrada por Doise (2001) e é compreensível, uma vez que faz parte das crenças religiosas idéias contrárias ao aborto e à eutanásia. É igualmente compreensível a influência positiva da Religião nos direitos de Defesa Pessoal (legítima defesa e propriedade), já que a religião católica no Brasil (religião dominante) defende os interesses relativos à propriedade - o setor mais tradicional da Igreja Católica defende os interesses dos latifundiários, todavia o setor mais de vanguarda, e que é o mais atuante, defende os interesses dos explorados. Historicamente, verifica-se que a Igreja Católica, a Conferência Nacional dos Bispos (CNB), as Pastorais, as Comunidades Eclesiais de Base (CEB), desde 1975, têm se envolvido nas lutas pelos DH. Já a influência negativa da Religião sobre os Direitos Concretos, que vai na direção oposta à influência encontrada por Doise (2001), só é compreensível se se considera que a religião no Brasil exerce, predominantemente, um papel conscientizador da população.

Ao contrário da Religião, a valorização dos Partidos Políticos mostra uma influência positiva nos direitos denominados Decisões Relativas à Vida e Protesto Social. Este resultado é semelhante ao obtido por Doise (2001). A influência positiva da valorização das Instituições Políticas sobre o Protesto Social é explicável quando se considera que os universitários que freqüentam as universidades públicas são influenciados a ter uma maior participação política (Da Costa et al., 1994) e que a participação política, por sua vez, influencia nos seus comprometimentos pessoais com os DH (Camino, Camino, Pereira, \& Paz, 2004).

A valorização das Organizações de Finanças teve um efeito negativo nos envolvimentos com os direitos referentes ao Protesto Social e aos direitos referentes a Decisões Relativas à Vida. Esses resultados são análogos àqueles obtidos por Doise (2001), em que uma atitude aversiva em relação ao poder e ao dinheiro, enquanto idéias de força, associava-se positivamente 
à escolha do Direito de Recusa.

As Associações Esportivas exerceram uma influência positiva sobre os Direitos Concretos. Em relação a esses resultados, deve-se ressaltar que, no Brasil, o esporte está associado não apenas ao lazer, mas ao status social e ao dinheiro, portanto ao consumismo.

A atitude favorável às Organizações Femininas influenciou positivamente os direitos ao Protesto Social, os direitos de Recusa de Controle Social e os Direitos Concretos, confirmando os obtidos por Doise (2001). Acredita-se que a influência sobre os dois primeiros tipos de direitos tem a ver com o fato de que a valorização de movimentos em prol das minorias significa também um maior nível de consciência política. Contudo, por que a influência positiva sobre os Direitos Concretos? Julga-se que a explicação aqui seja análoga àquela dada em relação às associações negativas, verificadas entre as Organizações de Defesa Social e os Direitos Concretos e de Protesto Social.

O Liberalismo influenciou positivamente todos os fatores referentes aos DH, com exceção do fator de Defesa Pessoal. Este resultado corrobora o obtido por Doise (2001), na medida em que este autor constatou que o coletivismo foi a atitude ideológica que mais influenciou aos direitos fundamentais, públicos e de recusa.

Finalmente, foi observado, através da ARM, realizada para analisar a ancoragem dos princípios organizadores no contexto social, que a região nordeste influenciou mais do que a região norte, e de forma positiva, o direito ao Protesto Social. Em relação à maior influência da região nordeste, deve-se considerar que, segundo dados de pesquisa realizada pelo Movimento Nacional dos Direitos Humanos, das 223 entidades e Comissões dos Direitos Humanos (CDHS) vinculados a este movimento, a região nordeste possui o maior número de filiações. Além disso, deve-se considerar que tem havido mais conquista de direitos sócio-econômicos por parte dos nordestinos do que por parte dos nortistas. Um exemplo é o caso da implantação da reforma agrária: enquanto no nordeste tem havido uma certa democratização do acesso à terra, no norte, segundo Maia (2001), tem havido uma maior concentração de terras (74\% da área) nas mãos de um menor número de pessoas $(5 \%)$.

\section{Considerações finais}

Uma reflexão geral sobre a discussão indica que os resultados da presente pesquisa, referentes ao envolvimento dos estudantes com os DH e aos princípios organizadores das RS dos $\mathrm{DH}$, assemelham-se, em grande parte, aos resultados obtidos em pesquisas com jovens genebreses (Doise, 2001; Doise et al., 1998), apesar das diferenças sócio-políticas entre os dois países. Este fato mostra que, não apenas o conhecimento sobre os DH goza de uma certa generalização (Clémence et al., 1995), mas também o nível de envolvimento com os $\mathrm{DH}$ e a forma como as pessoas organizam seus conhecimento sobre os DH. Portanto, pode-se concluir, que, pelo menos para uma grande parte da população, a DUDH tem sido difundida com eficácia, como foi a intenção dos países envolvidos com a sua proclamação em 1948, e que, por conseguinte, o conteúdo da DUDH faz parte das representações do senso comum, conforme a visão de Moscovici (2003). Infelizmente, esta valorização dos DH, numa perspectiva abstrata, não significa proteção efetiva dos $\mathrm{DH}$, pois além da proteção dos $\mathrm{DH}$ exigir decisões jurídicas, exige também um desenvolvimento da sociedade que desafia, segundo Bobbio (1992), até mesmo a Constituição mais evoluída.

Apesar de se ter observado certo consenso em relação ao posicionamento dos estudantes com respeito aos $\mathrm{DH}$, é importante destacar que ocorreram diferenças interpessoais, e que essas diferenças, em grande parte, foram explicadas pela ancoragem dos $\mathrm{DH}$ nas atitudes institucionais, nas simpatias ideológicas e no contexto social. Entretanto, a razão pela qual algumas instituições como a religião, a escola e a família exerceram uma influência diferente daquela constatada no estudo de Doise (2001) precisa ser melhor investigada. Um outro aspecto que merece esclarecimento diz respeito à influência negativa da Defesa Social, tanto em relação aos Direitos Concretos, como em relação ao Protesto Social. Enfim, acredita-se que seja importante investigar em futuras pesquisas a representação que as pessoas têm das instituições e o significado que têm para elas determinados direitos (como ter roupas, ter um cachorro, ter uma propriedade, etc.) que fazem parte do fator denominado Direitos Concretos.

\section{Agradecimentos}

Os autores agradecem o financiamento do CNPq e a colaboração dos professores Antônio Virgílio (UFBA), Antônia Dalva França Carvalho (UFPI), Clara Maria Santos (UFRN) e Jussara Lumertz (ULBRA).

\section{Referências}

Bobbio, N. (1992). A era dos direitos humanos. Rio de Janeiro: Campus. Camino, C. (2002). O pensamento moral e a valoração da vida em sociedade. Manuscrito não-publicado, Universidade Federal da Paraíba, João Pessoa.

Camino, C., Camino, L., Pereira, C., \& Paz, M. (2004). Moral, direitos humanos e participação social. Estudos de Psicologia, 9, 25-34.

Camino, C., Pereira, C., \& Paz, M. (2001). Estudos sobre a relação entre direitos humanos e julgamento moral de adolescentes paraibanos. In M. Zenaide \& L. Dias (Orgs), Formação em direitos humanos na universidade (pp. 79-86). João Pessoa: Editora da Universidade Federal da Paraíba.

Clémence, A., Doise, W., De Rosa, A. M., \& Gonzalez, L. (1995). La représentation sociale des droits de l'home: une recherche internationale sur 1'étendue et les limites de 1'universalité. Journal International de Psychologie, 30, 181-212.

Comparato, F. K. (1997). Fundamento dos direitos humanos. Obtido de http:// www.iea.usp.br/artigos, em 10 de março de 2007.

Da Costa, J., Torres, A., Burity, M., \& Camino, L. (1994). Universidade: espaço institucional para o desenvolvimento político. Temas, 1, 17-36.

Doise, W. (2001). Droits de l’homme et force des ideés. Paris: Presses Universitaires de France.

Doise, W. (2003). Human rights: common meaning and differences in positioning. Psicologia: Teoria e Pesquisa, 19, 201-210.

Doise, W., Clemence, A., \& Lorenzi-Cioldi, F. (1992). Représentations sociales et analyses de données. Grenoble: Presses Universitaires de Grenoble.

Doise, W., Staerklé, C., Clémence, A., \& Savory, F. (1998). Human rights and Genevan youth: a developmental study of social representations. Swiss 
Journal of Psychology, 57(2), 86-100.

Maia, L. (2001). Os direitos humanos e a experiência brasileira no contexto latinoamericano. In M. Zenaide \& L. Dias (Orgs.), Formação em direitos humanos na universidade (pp. 151-172). João Pessoa: Editora da Universidade Federal da Paraíba.

Moscovici, S. (2003). Representações sociais: investigações em psicologia social. Petrópolis: Vozes.
Núcleo de Estudos da Violência (2005). $3^{\circ}$ Relatório nacional sobre os direitos humanos no Brasil. Obtido de http://www.nevusp.org/downloads/down099. pdf, em 20 de março de 2007.

Zollo, D. (2006, setembro). A tutela internacional dos direitos humanos: entre as intervenções humanitárias e a jurisdição penal internacional. Comunicação apresentada no III Seminário Internacional de Direitos Humanos, João Pessoa, Paraíba.

\footnotetext{
${ }^{1}$. Localizada na região nordeste do Brasil.

${ }^{2}$. Localizada na região norte do Brasil.
}

Cleonice Pereira dos Santos Camino, doutora em Psicologia pela Université Catholique de Louvain (Bélgica), é professora na Universidade Federal da Paraíba. Endereço para correspondência: Rua da Aurora, 201, Ap. 908 (Miramar); João Pessoa, PB; CEP: 58043-270. Tel.: (83) 3224-5735, Fax: (83) 3216-7006. E-mail: cleocamino@yahoo.com.br

Lilian Kelly de Sousa Galvão, mestre em psicologia social pela Universidade Federal da Paraíba, e doutoranda em psicologia social pelo Doutorado Integrado em Psicologia Social UFPB-UFRN, é professora na Universidade Federal de Campina Grande. E-mail: liliangalvao@yahoo.com

Gina Gomes Quirino, mestre em Psicologia pela Universidade Federal do Rio Grande do Norte, é professora de psicologia na Faculdade Integral Diferencial (Teresina, Piauí).E-mail: ginagomes@yahoo.com Raquel Moraes de Lima Mangabeira, mestre em psicologia social pela Universidade Federal da Paraíba, é professora no Departamento de Direito, Centro de Humanidades, Universidade Estadual da Paraíba. E-mail: raquelmoraes@superig.com.br Antonio Roazzi, doutor pela Universidade de Oxford (Reino Unido), é professor associado na Universidade Federal de Pernambuco. Email: roazzi@pq.cnpq.br

William Lee Berdel Martin, doutor em Psicologia e Antropologia Biológica pela University of Illinois (EUA), é professor associado na Universidade Federal do Pará. E-mail: wlbmartin@gmail.com 


\section{Apêndice}

\section{Questionário sobre a vida na sociedade (extratos)}

[escalas elaboradas por Doise et al. (1998) e adaptadas por Camino (2002)]

Nós lhe apresentaremos agora alguns exemplos de direitos. Identifique, para cada um deles, em que medida trata-se, em sua opinião, de um bom ou mau exemplo de Direitos do Homem.

Dê uma resposta circulando o número que melhor corresponde à sua opinião.

$$
\begin{aligned}
& 1 \text { = mau exemplo } \\
& 2=\text { é mais para um mau exemplo do que para um bom exemplo } \\
& 3 \text { = é mais para um bom exemplo do que para um mau exemplo } \\
& 4=\text { bom exemplo }
\end{aligned}
$$

1. Direito à legítima defesa

2. Direito a esconder sua religião

3. Direito de fazer greve

4. Direito de ser o que quiser

5. Direito à propriedade

6. Direito de esconder uma doença contagiosa

7. Direito de ter quantas crianças quiser

8. Direito de receber cuidados médicos

9. Direito de recusar uma vacina

10. Direito a ser defendido(a) num tribunal por um advogado

11. Direito de fazer parte de um sindicato

12. Direito de organizar uma manifestação

13. Direito de ter o que comer

14. Direito a diversões

15. Direito de eleger o governo

16. Direito de ter um emprego

17. Direito de escolher suas roupas

18. Direito de discordar de suas notas na escola

19. Direito de abortar

20. Direito de viver com sua família

21. Direito de recusar o serviço militar

22. Direito de fumar

23. Direito de ter um cachorro

24. Direito de viver em um ambiente saudável

25. Direito de viver num mundo em paz

26. Direito de morar no país que se quer

27. Direito de apressar a morte de um doente terminal a que pede para morrer

28. Direito à proteção da polícia contra a violência

29. Direito de estudar

30. Direito de recusar ir para a escola

31. Direito de não ser discriminado pela sua cor

32. Direito de ter uma moradia

33. Direito de ter o que vestir

34. Direito de ter um salário digno

$\begin{array}{llll}1 & 2 & 3 & 4 \\ 1 & 2 & 3 & 4 \\ 1 & 2 & 3 & 4 \\ 1 & 2 & 3 & 4 \\ 1 & 2 & 3 & 4 \\ 1 & 2 & 3 & 4 \\ 1 & 2 & 3 & 4 \\ 1 & 2 & 3 & 4 \\ 1 & 2 & 3 & 4 \\ 1 & 2 & 3 & 4 \\ 1 & 2 & 3 & 4 \\ 1 & 2 & 3 & 4 \\ 1 & 2 & 3 & 4 \\ 1 & 2 & 3 & 4 \\ 1 & 2 & 3 & 4 \\ 1 & 2 & 3 & 4 \\ 1 & 2 & 3 & 4 \\ 1 & 2 & 3 & 4 \\ 1 & 2 & 3 & 4 \\ 1 & 2 & 3 & 4 \\ 1 & 2 & 3 & 4 \\ 1 & 2 & 3 & 4 \\ 1 & 2 & 3 & 4 \\ 1 & 2 & 3 & 4 \\ 1 & 2 & 3 & 4 \\ 1 & 2 & 3 & 4 \\ 1 & 2 & 3 & 4 \\ 1 & 2 & 3 & 4 \\ 1 & 2 & 3 & 4 \\ 1 & 2 & 3 & 4 \\ 1 & 2 & 3 & 4 \\ 1 & 2 & 3 & 4 \\ 1 & 2 & 3 & 4 \\ 1 & 2 & 3 & 4\end{array}$


Diga-nos, em sua opinião, em que medida as instituições e organizações seguintes podem ser úteis para você pessoalmente.

Dê sua resposta circulando o número que melhor corresponde à sua opinião.

$$
\begin{aligned}
& 1=\text { completamente inútil } \\
& 2=\text { não útil } \\
& 3=\text { útil } \\
& 4=\text { completamente útil }
\end{aligned}
$$
1. A família
2. A Cruz-Vermelha
3. Os movimentos ecológicos
4. Os partidos políticos
5. As associações esportivas
6. A religião
7. Os bancos
8. Os planos de saúde
9. A televisão
10. Os tribunais
11. A Organização das Nações Unidas
12. Os jornais
13. Os hospitais
14. A escola
15. As organizações femininas

$\begin{array}{llll}1 & 2 & 3 & 4 \\ 1 & 2 & 3 & 4 \\ 1 & 2 & 3 & 4 \\ 1 & 2 & 3 & 4 \\ 1 & 2 & 3 & 4 \\ 1 & 2 & 3 & 4 \\ 1 & 2 & 3 & 4 \\ 1 & 2 & 3 & 4 \\ 1 & 2 & 3 & 4 \\ 1 & 2 & 3 & 4 \\ 1 & 2 & 3 & 4 \\ 1 & 2 & 3 & 4 \\ 1 & 2 & 3 & 4 \\ 1 & 2 & 3 & 4 \\ 1 & 2 & 3 & 4\end{array}$

Diga-nos, na sua opinião, em que medida estas mesmas instituições e organizações são úteis para viver com os outros sem tantos problemas.

Dê sua resposta circulando o número que melhor corresponde à sua opinião.

$1=$ completamente inútil

$2=$ não útil

$3=$ útil

$4=$ completamente útil

1. A família

2. A Cruz-Vermelha

3. Os movimentos ecológicos

4. Os partidos políticos

5. As associações esportivas

6. A religião

7. Os bancos

8. Os planos de saúde

9. A televisão

10. Os tribunais

11. A Organização das Nações Unidas

12. Os jornais

13. Os hospitais

14. A escola

15. As organizações femininas

$\begin{array}{llll}1 & 2 & 3 & 4 \\ 1 & 2 & 3 & 4 \\ 1 & 2 & 3 & 4 \\ 1 & 2 & 3 & 4 \\ 1 & 2 & 3 & 4 \\ 1 & 2 & 3 & 4 \\ 1 & 2 & 3 & 4 \\ 1 & 2 & 3 & 4 \\ 1 & 2 & 3 & 4 \\ 1 & 2 & 3 & 4 \\ 1 & 2 & 3 & 4 \\ 1 & 2 & 3 & 4 \\ 1 & 2 & 3 & 4 \\ 1 & 2 & 3 & 4 \\ 1 & 2 & 3 & 4\end{array}$


Para cada uma das palavras seguintes, diga-nos se você gosta do que elas representam; se você desconhece uma palavra circule o número zero.

Para cada palavra, nós lhe pedimos para circular o número que melhor corresponde à sua opinião:

1 = eu não gosto de forma nenhuma

2 = eu não gosto muito

$3=$ eu gosto

$4=$ eu gosto muito

$0=$ eu desconheço

1. A democracia

2. A igualdade

3. O poder

4. As tradições

5. Partidos de esquerda

6. O dinheiro

7. Os direitos do homem

8. Partidos de direita

9. A solidariedade

10. A liberdade

$\begin{array}{lllll}1 & 2 & 3 & 4 & 0 \\ 1 & 2 & 3 & 4 & 0 \\ 1 & 2 & 3 & 4 & 0 \\ 1 & 2 & 3 & 4 & 0 \\ 1 & 2 & 3 & 4 & 0 \\ 1 & 2 & 3 & 4 & 0 \\ 1 & 2 & 3 & 4 & 0 \\ 1 & 2 & 3 & 4 & 0 \\ 1 & 2 & 3 & 4 & 0 \\ 1 & 2 & 3 & 4 & 0\end{array}$

